\title{
Plug cartilage tympanoplasty in children
}

José Arruda Mendes Neto ${ }^{1}$, Felipe Costa Neiva ${ }^{2}$, Fábio Brodskyn 3 , Marcel das Neves Palumbo ${ }^{4}$ Ana Cláudia Valério Bittar5, Roberta Novaes Borges Petrilli, José Ricardo Gurgel Testa ${ }^{7}$
Keywords: cartilage, tympanic membrane, tympanoplasty.

\section{Summary}

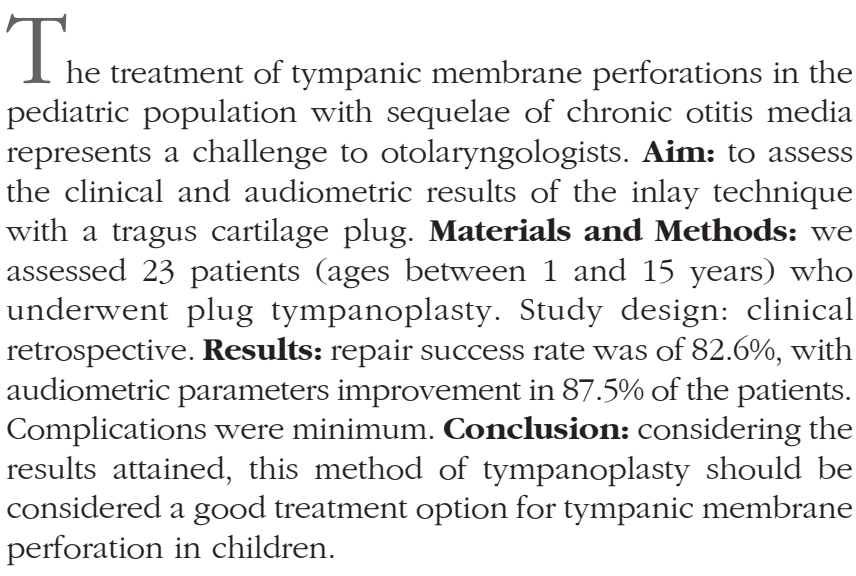

${ }^{1}$ MD. Otorhinolaryngology resident - UNIFESP-EPM.

${ }^{3}$ MD. Otorhinolaryngology resident - UNIFESP-EPM.

${ }^{4} \mathrm{MD}$. Otorhinolaryngology resident - UNIFESP-EPM.

${ }^{5}$ MD. Otorhinolaryngologist. MSc. Student - Department of Otorhinolaryngology - Head and Neck Surgery - UNIFESP/EPM.

${ }^{6}$ MD. Otorhinolaryngologist. MSc. Student - Department of Otorhinolaryngology - Head and Neck Surgery - UNIFESP/EPM. $7 \mathrm{PhD}$, Adjunct Professor - Department of Otorhinolaryngology - Head and Neck Surgery - UNIFESP/EPM.

Send correspondence to: José Arruda Mendes Neto - Rua Jorge Tibiriça 229 apto 61 Vila Afonso Celso 04126-000.

This paper was submitted to the RBORL-SGP (Publishing Manager System) on 15 July 2007. Code 4658. The article was accepted on 9 September 2007. 


\section{INTRODUCTION}

The first known attempt to repair an ear drum perforation was allegedly made by Banzer, in 1640, using a swine bladder membrane graft1. In 1853, Toynbee introduced the "artificial eardrum", a small rubber disk with a silver rod - to facilitate introduction and extraction ${ }^{1-3}$. In 1878, Berthold, used a skin graft and in 1887, Blake recommended the use of a piece of paper as a template to tympanic membrane regeneration1. Notwithstanding, it was only after 1944, with the beginning of antibiotics and with the improvement in surgical techniques that other materials were used as grafts in tympanoplasties ${ }^{1,2}$. After this time, in 1952, Zollner and Wullstein published their methods, using retroauricular skin grafts; however they did not succeed in treating tympanic membrane perforations $s^{1,2,4,5,6}$.

Brazilian data, published by Costa in 1976, showed good results in the treatment of tympanic membrane perforations with the use of temporal fascia grafts and dura mater grafts 7 . In 1983, Miniti et al., showed a significant audiometric improvement in patients submitted to tympanic membrane repair surgery with the use of dura matter ${ }^{8}$. In 2003, Oliveira et al. Observed that the use of synthetic biomaterial (latex biomembrane with polylysine) could contribute to a greater graft take rate of temporal fascia in tympanoplasties?.

Thus, numerous types of tympanoplasty grafts have been described. The most commonly used techniques for graft placement on the tympanic membrane are the "underlay" (medial) and "onlay" (lateral), and the most used types of graft are the temporal muscle fascia and perichondrium, with similar success rates (approximately $90 \%)^{4,5}$. Among children, these rates vary between 66 and $93.5 \%$ with the use of temporal fascia graft ${ }^{10}$. However, these two techniques require a skin incision in the external acoustic meatus (EAM), which causes greater morbidity and the need for better post-op care, reducing the use of these techniques in children ${ }^{6,11}$. In 1989, Gross described the "inlay" approach, with the use of a fat tissue plug for small perforations, however without success in repairing the perforations ${ }^{12}$.

The cartilage was first used to rebuild the ossicular chain in 1958, by Jansen ${ }^{13}$. Some years later, this material started to be used as a graft in tympanoplasties, especially in cases of advanced middle ear diseases, because of their robustness, offering greater resistance to resorptions $s^{4}$. In 1998, Eavey described tympanoplasty in children using the tragal cartilage and bilateral perichondrium (cartilage plug) and the placement of a graft without incisions in the EAM (inlay approach) ${ }^{11}$. This new approach, when compared to the previous ones, showed a number of advantages for its use in children: no need for a tympanic-meatal flap, reducing pain and the need for post-op care; possibility of placing the graft in the so called "hostile" ear drums (those with tympanosclerosis plaques and malleus exposure); shorter surgical time, it can be carried out under general anesthesia without orotracheal intubation, thus giving the patient the possibility of an early hospital discharge - and reducing costs - no need to dress the EAM, since the graft fits stable onto the ear drum ${ }^{6,11}$.

The goal of the present investigation is to assess the clinical and audiometric results of the inlay approach with tragus cartilage plug to correct tympanic membrane perforations in the pediatric population.

\section{MATERIALS AND METHODS}

We carried out a retrospective study, through the analyses of medical charts from 23 patients with tympanic membrane perforations, operated from October of 1999 through September of 2005. All the patients had the following characteristics: 1- age below 16 years, 2- central perforation with possibility to visualize all its borders, 3tympanic membrane perforation caused by chronic otitis media, 4- disease in one ear only, 5- conductive hearing loss with air-bone gap below $50 \mathrm{~dB}$.

The patients were broken down in two groups: age below or equal to 10 years $(n=11)$, and one group of older patients $(n=12)$, since the rate of upper airway infections is considered higher in the first group.

All the patients were assessed through a clinical history, general and otorhinolaryngological physical exam, audiometry, image exams (temporal bone CT scan) when necessary and preoperative tests. The mean value of tonal audiometries was calculated using the values from $500 \mathrm{~Hz}, 1 \mathrm{kHz}, 2 \mathrm{kHz}, 4 \mathrm{kHz}$ in a study of the air and bone conduction curves.

The microscope used in the surgical procedure had a video camera coupled to it, allowing for high quality documentation of the procedure. Through this latter resource, it was possible to measure perforation size in percentage through the following calculation: perforation area /total area of the tympanic membrane X 100.

Cartilage plug tympanoplasty postoperative results were evaluated as to perforation closure, need for further surgeries, hearing improvement checked by means of the audiometry and the presence of postoperative complications.

Patients were observed for an average time period of nine months after surgery, varying between three to twelve months.

Statistical analyses were carried out using the chisquare with correction by Fisher's exact test.

This study was analyzed and approved by the Research Ethics Committee of our institution, under protocol \# 20070820101245. 


\section{TECHNIQUE}

With the patient under general anesthesia and under microscopic view, we examined the tympanic membrane perforation (Fig.1). The perforation border was removed with a straight tip stylet and, later on, a curved tip stylet was used to scratch the mucosal face of the tympanic membrane. The perforation's size and shape were measured with the help of a hook-type stylet, drawing its shape in a piece of sterile paper (nylon suture wire wrapping which was used later to close the tragal incision -donor site). The paper was cut and the perforation size was checked against the paper mold created.

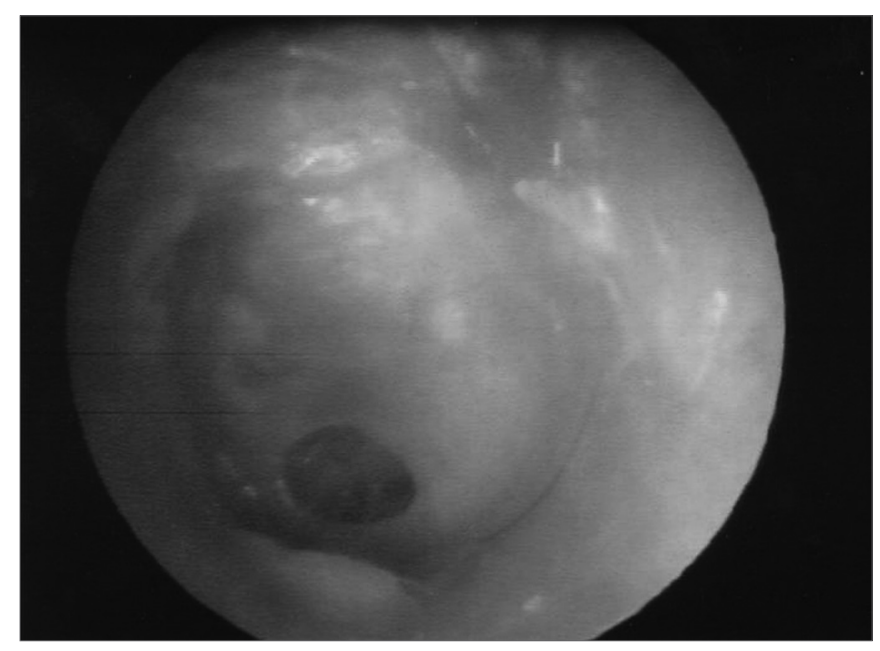

Figure 1. Central perforation in the tympanic membrane.

A small, one centimeter incision, was made across the tragus ( 15 scalpel blade). We used a delicate scissors to dissect the tragus inferior cartilage preserving the perichondrium in both sides, and we removed a fragment slightly larger than the mold we had previously created. This incision was sutured up with 5-0 nylon wire.

Using the same $\# 15$ scalpel blade, we cut the entire perimeter of the graft, making a small $2 \mathrm{~mm}$-deep sulcus in it (Fig.2). Following that, the graft was placed on the perforation with perfect fitting. (Fig.3). On top we placed a thin gelfoam layer with antibiotic ointment, and a cotton ball was used to seal the EAM.

With one week of post-op, the suture was removed and the gelfoam fragments were aspirated, allowing us to see the graft and its viability ${ }^{2,4,11}$ (Fig. 4).

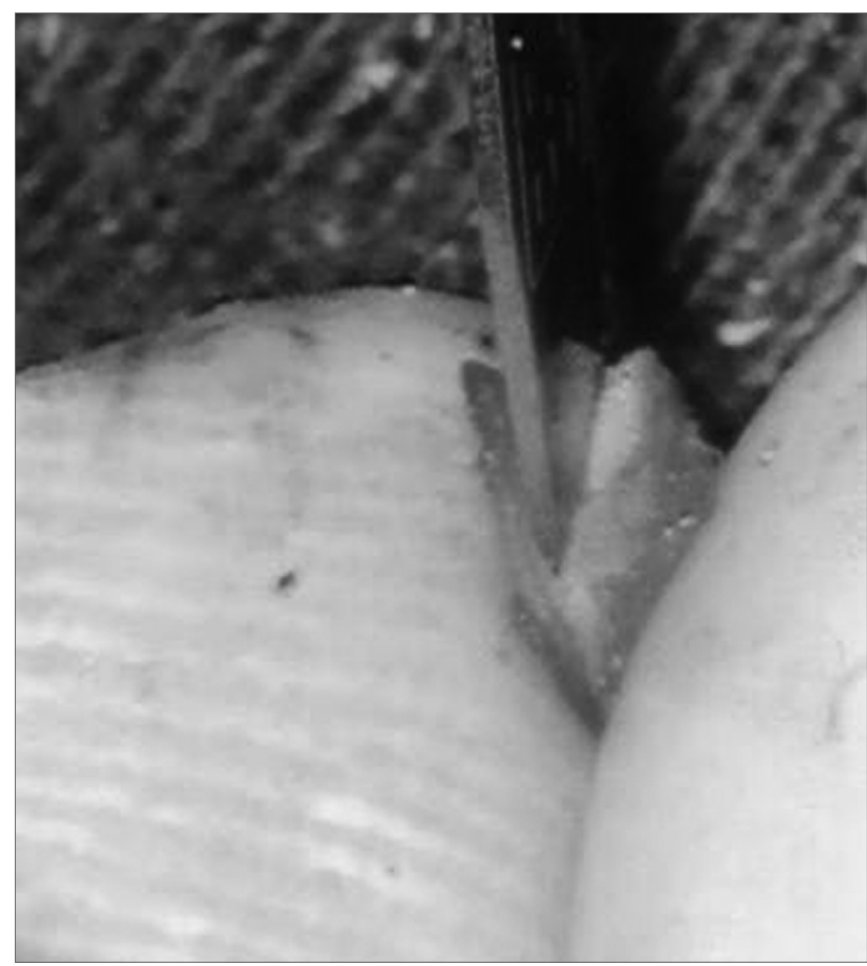

Figure 2. Creating a sulcus in the cartilage graft.

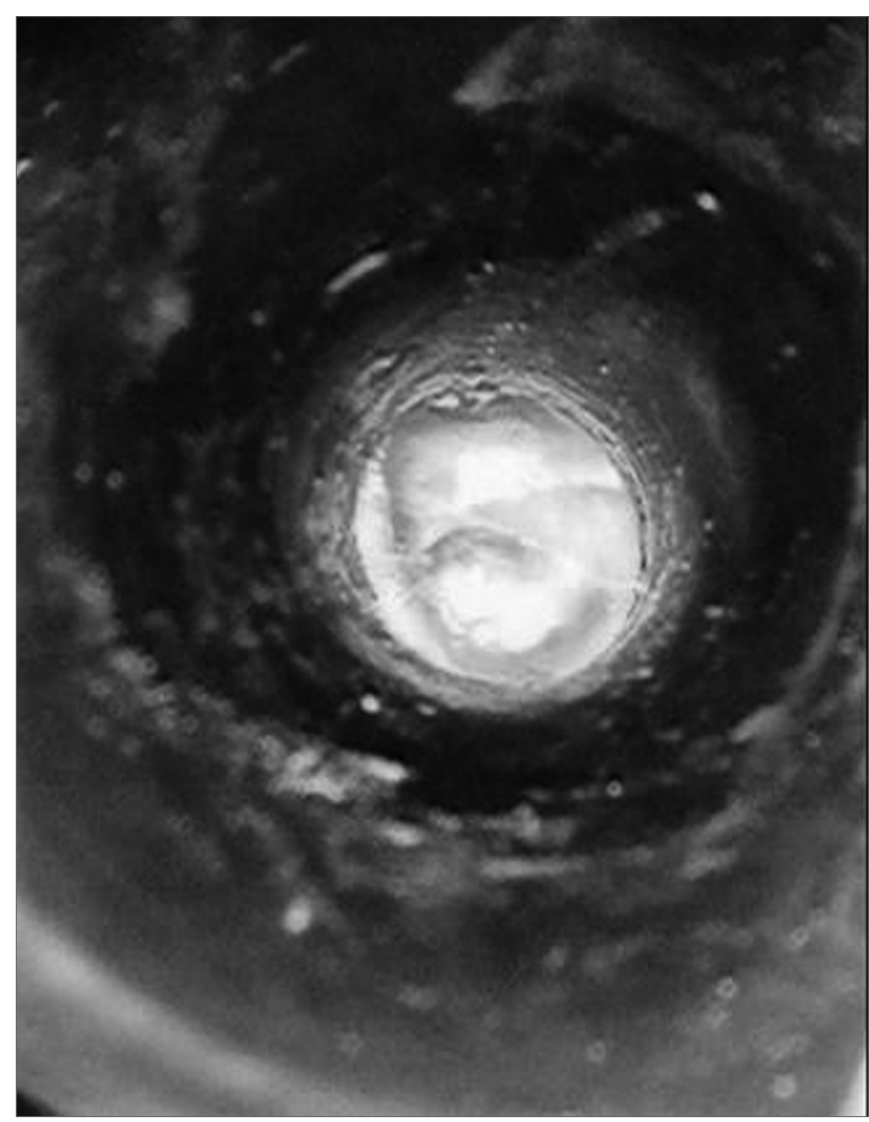

Figure 3. Plug fitting perfectly on the ear drum perforation. 


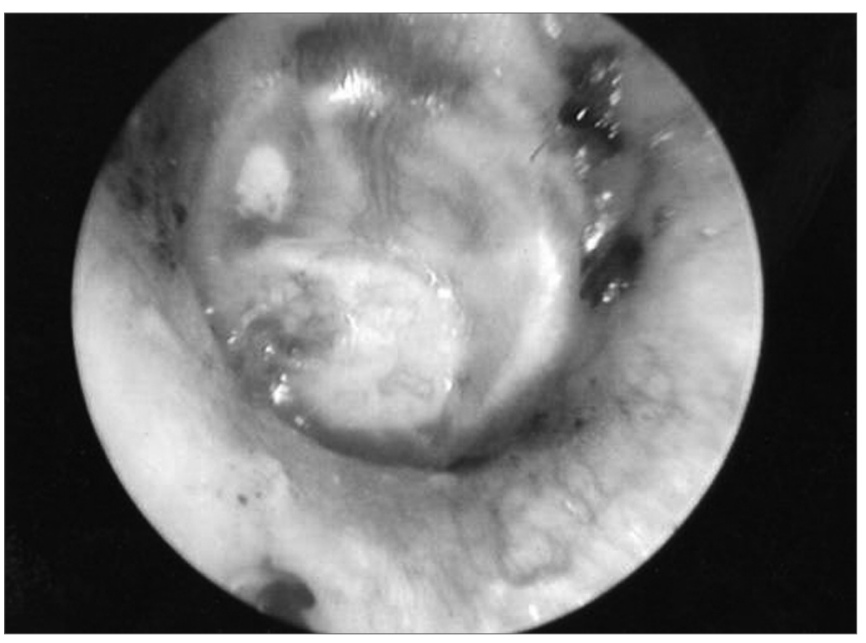

Figure 4. Otoscopic view one week after surgery.

\section{RESULTS}

From a total of 23 patients submitted to tympanoplasty with cartilage plug, 14/23 were males (65.4\%) and $9 / 23(34.6 \%)$ were females, with ages ranging from 3 to 15 years, with mean value of 10.3 years. In the group of patients between one and ten years of age, there were 8/12 (66.7\%) males and only 4/12 (33.3\%) females (Table 1). The left side was involved in 10 cases (43.4\%), while the right side was affected in 13 cases (56.6\%).

30 cartilage plug tympanoplasties were carried out in these 23 patients, and in seven of them (30.4\%) it was necessary to reoperate in order to close the perforation, and in six of them the reoperation was successful. Of these seven, only one was between 1-10 years of age.
Mastoidectomies were also necessary in order to open the antrum and attic in six individuals (26.1\%).

Perforation sizes varied from $15 \%$ to $90 \%$. In the $1-10$ year-olds this variation was of 15 to $25 \%$ (mean value of $29.3 \%$ ), while in the other group this variation was higher (25 to 90\%), with a mean value of $48 \%$ (Table 2).

In the initial auditory evaluation, we observed a minimum air-bone gap of $5 \mathrm{~dB}$ and maximum of $30 \mathrm{~dB}$ in the group with 1-10 years of age (mean value of $16.3 \mathrm{~dB}$ ) and, in the final postoperative evaluation, a minimum difference of $0 \mathrm{db}$ and maximum of $15 \mathrm{~dB}$ (mean value of $5 \mathrm{~dB}$ ). In the other group, the preoperative values varied between $5 \mathrm{~dB}$ and $50 \mathrm{~dB}$ (mean value of $26.6 \mathrm{~dB}$ ). In the postoperative there was a variation of 0 to $30 \mathrm{~dB}$ (mean value of $12.4 \mathrm{~dB}$ ). In three patients there was no gap improvement with tympanoplasty, all of them belonged to the group of older patients (Table 2).

Among the patients submitted to the procedure, we observed one postoperative complication - this individual had local infection with improvement of signs and symptoms through clinical measures, however the perforation remained, without gap improvement.

There was total perforation closure in 19 patients (82.6\%). We observed residual perforation in four patients (17.4\%) during the follow up period, and half of them belonged to the group of younger patients. There was no statistically significant difference between the two groups studied (Table 3).

The age range did not impact air-bone thresholds after surgery, as seen on Table 4 .

And finally, tympanoplasty was effective in improving the gap alone in each group, according to the table below (Table 5).

Table 1. Patients' traits.

\begin{tabular}{lccc}
\hline & $1-10$ years group & $11-15$ years group & Total \\
\hline $\begin{array}{l}\text { Number of patients } \\
\text { Gender }\end{array}$ & 11 & 12 & 23 \\
males & 5 & 8 & 14 \\
females & 5 & 4 & 9 \\
Age (years) & & & 10,3 \\
mean & 7,3 & 12,8 & $(3 " 15)$ \\
Variation & $(3-9)$ & $(11-15)$ & 13 \\
Perforation side & & & 10 \\
Right & 5 & 4 & 10 \\
Left & 6 & & \\
\hline
\end{tabular}


Table 2. Perforation and air-bone gap in the two groups studied.

\begin{tabular}{lcc}
\hline & $1-10$ years Group & 11-15 years Group \\
$(\mathrm{n}=12)$ & $12)$ & \\
Perforation size & & $48 \%$ \\
Mean & $29,3 \%$ & $25-90 \%$ \\
Variation & $15-25 \%$ & \\
Preoperative gap & & $26,6 \mathrm{~dB}$ \\
Mean & $16,3 \mathrm{~dB}$ & $5-50 \mathrm{~dB}$ \\
Variation & $5-30 \mathrm{~dB}$ & \\
Postoperative gap & & $12,4 \mathrm{~dB}$ \\
Mean & $5 \mathrm{~dB}$ & $0-30 \mathrm{~dB}$ \\
Variation & $0-15 \mathrm{~dB}$ & $9(75 \%)$ \\
Gap improvement & $11(100 \%)$ & \\
\hline
\end{tabular}

Table 3. Residual perforation after tympanoplasty in the two groups studied.

\begin{tabular}{lcc}
\hline & $\begin{array}{c}1-10 \text { years group } \\
(\mathrm{n}=11)\end{array}$ & $\begin{array}{c}11-15 \text { years group } \\
(\mathrm{n}=12)\end{array}$ \\
$\begin{array}{l}\text { Residual perforation } \\
\text { after tympanoplasty }\end{array}$ & $2(18,2 \%)$ & $2(16,7 \%)$ \\
\hline
\end{tabular}

Fisher's exact test: $\mathrm{p}$-value $=0.67$

Table 4. Age range influence on the air-bone gap improvement after tympanoplasty.

\begin{tabular}{lcc}
\hline & $\begin{array}{c}1-10 \text { years group } \\
(\mathrm{n}=11)\end{array}$ & $\begin{array}{c}11-15 \text { years group } \\
(\mathrm{n}=12)\end{array}$ \\
$\begin{array}{l}\text { s15dB gap after } \\
\text { tympanoplasty }\end{array}$ & $6(54,5 \%)$ & $3(25 \%)$ \\
$\begin{array}{l}\leq 15 \mathrm{~dB} \text { gap after } \\
\text { tympanoplasty }\end{array}$ & $11(100 \%)$ & $9(75 \%)$ \\
\hline
\end{tabular}

Fisher's exact test: $p$-value $=0.43$

Table 5. Results from tympanoplasty according to age groups.

\begin{tabular}{lcccc}
\hline & \multicolumn{2}{c}{$\begin{array}{c}1-10 \text { years group } \\
(\mathrm{n}=11)\end{array}$} & \multicolumn{2}{c}{$\begin{array}{c}11-15 \text { years group } \\
(\mathrm{n}=12)\end{array}$} \\
\hline & $\begin{array}{c}\text { gap } \\
\leq 15 \mathrm{~dB}\end{array}$ & $\begin{array}{c}\text { gap } \\
>15 \mathrm{~dB}\end{array}$ & $\begin{array}{c}\text { gap } \\
\leq 15 \mathrm{~dB}\end{array}$ & $\begin{array}{c}\text { gap } \\
>15 \mathrm{~dB}\end{array}$ \\
$\begin{array}{l}\text { Before } \\
\text { tympanoplasty }\end{array}$ & $6(54,5 \%)$ & $5(45,5 \%)$ & $3(25 \%)$ & $9(75 \%)$ \\
$\begin{array}{l}\text { After } \\
\text { tympanoplasty }\end{array}$ & $11(100 \%)$ & $0(0 \%)$ & $9(75 \%)$ & $3(25 \%)$ \\
\hline
\end{tabular}

Fisher's exact test: $\mathrm{p}$-value $=0.01$ ( $1-10$ years Group)

P-value $=0.01$ ( $11-15$ years Group)

DISCUSSION

Cartilage, as well as fascia, vein and periosteum are mesenchymal tissues and, for this very reason, they do not scale off. They have no secretory glands, nor hair follicles as those found in the skin, thus being used as tympanic membrane graft without the risk of causing iatrogenic cholesteatomas ${ }^{1}$.

Contrary to other materials, cartilage has some physical properties that facilitate its use in tympanoplasties. These grafts are nourished by diffusion and easily incorporated on the tympanic membrane, which has been confirmed in second look tympanoplasties ${ }^{4-6}$. It is a more robust material, easier to fit on the ear drum perforation site1. It is thicker, less prone to resorption and retraction ${ }^{4}$. Nonetheless, the cartilage acoustic transfer characteristics are theoretically worse because of its thickness ${ }^{2,4,6}$. In 2000, Zahnert et al. carried out an experimental study concluding that a $500 \mu m$-thick cartilage has an acceptable acoustic transfer capacity with good mechanical stability ${ }^{14}$.

Success rates of tympanic membrane perforation closure with cartilage plugs in adults are high. In 2000, Testa et al., published a closure success rate of $96.8 \%$ with hearing improvement in all the cases ${ }^{2}$. Lubianca-Neto et al. in 2000, published rates of $90 \%$ and $94.4 \%$, respectively ${ }^{6}$. These are the goals to be reached in children.

Notwithstanding, low immunity, high upper airway infection rate and Eustachian tube dysfunction are factors responsible for reducing the success rates of tympanoplasties in the pediatric population ${ }^{3}$.

In the present investigation we found a total perforation closure in 19/23 patients, with a success rate of $82.6 \%$. In the younger group, this rate was of $81.8 \%$, while in the other group it was of $83.3 \%$. These rates are similar to the ones found by Hennawi in 2001 and Couloigner et al. in $2005^{3,10}$. There was no statistically significant difference between the two groups studied $(p>0.05)$. This fact 
is probably due to the larger size of perforations in the older group, while in the younger group there are more factors inherent to their age range that impair graft take after surgery.

Twenty patients (87.5\%) had hearing improvement after tympanoplasty. In the youngest one there was a mean gap reduction from $13.6 \mathrm{~dB}$ to $5 \mathrm{~dB}$, with threshold improvement in all the patients. In the other ones, there was a mean gap reduction from $26.6 \mathrm{~dB}$ to $12.4 \mathrm{~dB}$, with threshold improvements in 9/12 patients. The other three patients remained with bone-gap differences equal to the ones they had before surgery. These results are similar to the ones published by Couloigner et al. in $2005^{10}$. Therefore, regardless of the group studied and despite the cartilage graft density, hearing results are very good $(p<0.01)$.

Of the seven patients who were reoperated, there was perforation closure in six of them, and only one case belonged to the 1-10 year-olds group. This shows that such procedure bears good results both in primary surgeries as it does with reoperations.

The smaller perforations, the shortest preoperative gaps and the high perforation closure success rates and hearing improvement indicate that this type of approach can be carried out as early as possible to treat sequelae of chronic otitis media in the pediatric population. Moreover, differently from other approaches, this one does not require major postoperative care and cause less pain because it does not require the physician to dissect a tympanic-meatal flap. This makes the tragus cartilage plug procedure a good option for the treatment of ear drum perforations. Complications were rare in some of the papers published, as they were in our study ${ }^{2,4,11}$.

Perforation closure success rates are similar to those achieved with other materials used, such as the temporal fascia. There was no statistically significant difference as to the closure of perforations and hearing improvement between cartilage plug tympanoplasty and that carried out with temporal fascia in the study published by Couloigner et al. in $2005^{10}$. Eavey in 1998 and Levinson in 1987 also showed success rates very similar to these when other materials were compared to cartilage plug ${ }^{4,15}$.

\section{CONCLUSION}

1. Tragus cartilage plug tympanoplasty was an effective approach to close tympanic membrane perforations in $82.6 \%$ of the patients from a pediatric population.

2. There was hearing improvement in $87.5 \%$ of the individuals.

3. Age range did not have a significant influence on the clinical and audiometric results obtained after surgery in the two groups studied.

\section{REFERENCES}

1. Evitar A. Tragal perichondrium and cartilage in reconstructive ear surgery. Laryngoscope 1978;88:1-23.

2. Testa JRG, Teixeira MS, Ribeiro KMX, Pizarro GU, Millas I. Cartilagem tragal com pericôndrio em timpanoplastias. Rev Bras Otorrinolaringol 2002;68:920-5.

3. Hennawi DM. Cartilage Perichondrium Composite graft (CPCG) in pediatric tympanoplasty. Int $\mathrm{J}$ of Pediatr Otorhinolaryngol 2001;59:1-5.

4. Gerber MJ, Mason JC, Lambet PR. Hearing results after primary cartilage tympanoplasty. Laryngoscope 2000;110:1994-9.

5. Dornhoffer JL. Hearing results with cartilage tympanoplasty. Laryngoscope 1997;107:1094-9.

6. Lubianca Neto JF. Inlay butterfly cartilage tympanoplasty (Eavey technique) modified for adult. Otolaryngol Head Neck Surg 2000;123:492-4.

7. Costa EA. Estudo comparativo entre o enxerto de fáscia e o implante de dura-máter nas timpanoplastias. Rev Bras Otorrinolaringol 1970;44:218-22.

8. Minitti A, Souza JCR, Cruz OLM, Paiva LJ. Uso de dura-máter em timpanoplastia. Rev Bras Otorrinolaringol 1983;49:37-9.

9. Oliveira JAP, Hyppolito MA, Netto JC, Mrué F. Miringoplastia com utilização de um novo material biossintético. Rev Bras Otorrinolaringol 2003;69:649-55.

10. Couloigner V, Bauculard F, Bakkouri W, Viala P, Francois M, Narcy $\mathrm{P}$, Abbeele VD. Inlay butterfly cartilage tympanoplasty in children. Otol Neurotol 2005;26:247-51.

11. Eavey RD. Inlay tympanoplasty: cartilage butterfly technique. Laryngoscope 1998;108:657-61.

12. Gross CW, Bassela M, Lazar RH, Long TE, Stagner S. Adipose plugue myringoplasty: an alternative to formal myringoplasty techniques in children. Otolaryngol Head Neck Surg 1989;101:617-20.

13. Janse C. Cartilage - tympanoplasty. Laryngoscope 1963;73:1288 302.

14. Zahnert T, Huttenbrink KB, Murbe D, Bornitz M. Experimental investigations of the use of cartilage in tympanic membrane reconstruction. American J Otol 2000;21:322-8.

15. Levinson R. Cartilage - Perichondrial composite graft tympanoplasty in the treatment of posterior marginal and attic retractions pockets. Laryngoscope 1987;97:1069-74. 